\title{
Spontaneous seizures in the Mongolian gerbil
}

\section{(Meriones unguiculatus)'}

D. D. THIESSEN, G. LINDZEY, AND H. C. FRIEND, DEPARTMENT OF PSYCHOLOGY, UNIVERSITY OF TEXAS, Austin, Tex. 78712

Approximately 50\% of the Mongolian gerbils in our colony were observed to display an epileptiform seizure when placed in a novel area. Forty-six percent of the susceptible animals were descended from two pairs of animals. Stimulus quality seemed to have little bearing on the response, but stimulus intensity was important. Daily exposure to novelty resulted in a progressive loss of seizure activity until no seizures were observed by the fifth day. The peak seizure time was at the height of diurnal behavioral activity. Dilantin, a common anticonvulsant drug used in human epilepsy completely eliminated the seizure as did reserpine. Brain histologies revealed nothing peculiar about the seizing animals. Neither dietary deficiencies nor infections seemed to be involved. The seizure pattern and the conditions under which it occurred suggest a variable genetic threshold response contingent on central nervous system excitation.

"Spontaneous" seizures have been noted in several species including man, but in no case are the proximal inducers clearly known (Barnett, 1964; King, 1939; King, Lee, \& Visscher, 1955; Richter, 1957). After noting several convulsions of the gerbil (Meriones unguiculatus) in our laboratory, we at tempted to clarify the conditions that evoke and suppress the response.

\section{EXPERIMENT 1}

\section{NATURE AND FREQUENCY OF SEIZURES}

Procedure. The first step upon noting seizures was to screen all of our gerbils (one to 18 months of age) under standard test conditions. Each animal was placed for $5 \mathrm{~min}$ in an open field (arena) containing regularly spaced barriers.

$51.2 \mathrm{~cm} \mathrm{sq}$, lined off in 25 squares each $10.2 \mathrm{~cm} \mathrm{sq}$. Twelve barriers $12.8 \mathrm{~cm}$ high (corresponding to the height of the surrounding walls) were placed at intervals throughout the arena which was painted gray. Testing was done in a well-lighted room between approximately 9:00 AM to 2:00 PM.

Results. Thirty-three of the 123 gerbils tested $(27 \%)$ seized. The seizure was quite stereotyped. Within a few seconds the vibrissae and ears twitched, and a full tonic-clonic seizure usually ensued with a rostral-caudal progression. On a 5-point scale, with 5 indicating the judgment of the most severe seizure, the average intensity of the response was $2.5 \pm 1.2$, latency to the beginning of the seizure (nose and ear twitch) $48.8 \pm 46.9 \mathrm{sec}$, length of overt convulsion $29.6 \pm 23.0 \mathrm{sec}$ and latency to full recovery after seizure 108.0 \pm 101.8 . During the period of recovery the animals were flexy-catatonic and their extremities could be molded into permanent positions. There were no sex differences in incidence of seizure. Lengthening the period of observation did not increase the number of seizures found.

\section{EXPERIMENT 2}

STIMULUS CHARACTERISTICS EVOKING SEIZURES

Procedure. An attempt was made to isolate the stimulus characteristics precipitating the seizure. For this test 20 seizureprone gerbils (designated from the test described above) and 20 non-seizing gerbils were divided into four groups of five seizing and five nonseizing animals. Sexes were distributed across groups. The stimulus conditions to which the animals were exposed were: open-field with black floor (A), open-field with white floor (B), confined field with black floor (C), and confined field with white floor (D). The open field was $92.2 \mathrm{~cm}$ sq and the confined field was $15.4 \mathrm{~cm}$ sq. Gray vertical walls $46.1 \mathrm{~cm}$ enclosed the fields. The order of presentation was partially counter-balanced so that all gerbils experienced each stimulus configuration but not in the same order.

Results. No condition was any more likely to induce seizures than any other. The number of animals seizing were $A=5, B=4$,
$C=4$, and $D=3$. All were from the original group designated to be seizure-prone. No sex differences were evident. On a more casual basis we have found that handling, cage cleaning, bright lights and exposure to activity wheels and the visual cliff can all elicit seizures.

\section{EXPERIMENT 3}

\section{HABITUATION OF SEIZURE}

Procedure and Results. Beginning one week after the last test, 20 seizure-prone gerbils were tested in the open field (Condition $\mathbf{A}$ above) for $5 \mathrm{~min}$ on each of four consecutive days and their performance compared to original performance in the arena. On the fifth day the animals were again observed in the arena. As indicated in Fig. 1, there was a progressive drop in the per cent of gerbil seizing with each test until finally there was a zero incidence. The test in the arena on the last day indicates that the habituation had generalized to the original test environment where previously all animals had seized.

Subsequently these same seizure-prone gerbils were tested four times in Condition $\mathbf{A}$ with one week intervening between each test. The proportion of animals seizing on each successive test remained about the same (i.e., 32\%, 36\%, 35\%, and 40\%). It could not be predicted from week to week which particular animals would seize. Thus seizure inhibition due to continual testing was partially disinhibited by stimulus deprivation. Moreover, disinhibition seemed to be a population characteristic and not based on individual variations.

\section{EXPERIMENT 4}

\section{DIURNAL CYCLE OF SEIZURE SUSCEPTIBILITY}

Procedure and Results. The tests described above were conducted between 9:00 AM and 2:00 PM. If convulsions depend upon the arousal level of the animal as these studies suggest, it would be expected that seizure frequency and intensity would be higher during the night when behavioral activity is greater. Our initial observations supported this notion. Of 120 gerbils tested during a two week period either between 9:00 AM to 2:00 PM (light period) or 9:00 PM to 2:00 AM (dark period), 27 seizures (33\%) were observed during the light period and 54 seizures $(67 \%)$ were observed during the dark period. Moreover, the cumulative per cents of seizures in 20 gerbils tested every $2 \mathrm{~h}$ beginning at 10:00 PM were 45,85 , and 100 . Considering the usual adaptation that occurs with repeated testing, these results strongly suggest a heightened seizure susceptibility as the night progresses.

We now know from other data that behavioral activity is greatest between 12:00 $\mathrm{M}$ and 2:30 AM. On the basis of this information we tested independent groups of seven seizure-prone

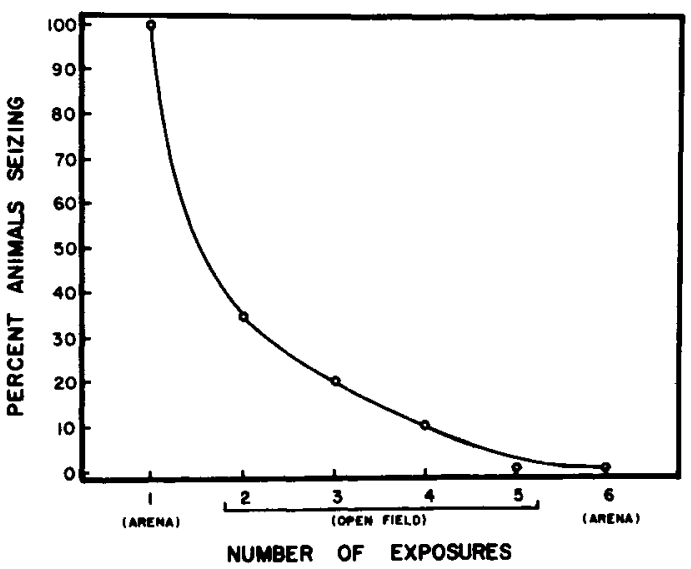

Fig. 1. Diminution of seizure susceptibility with daily testing. 


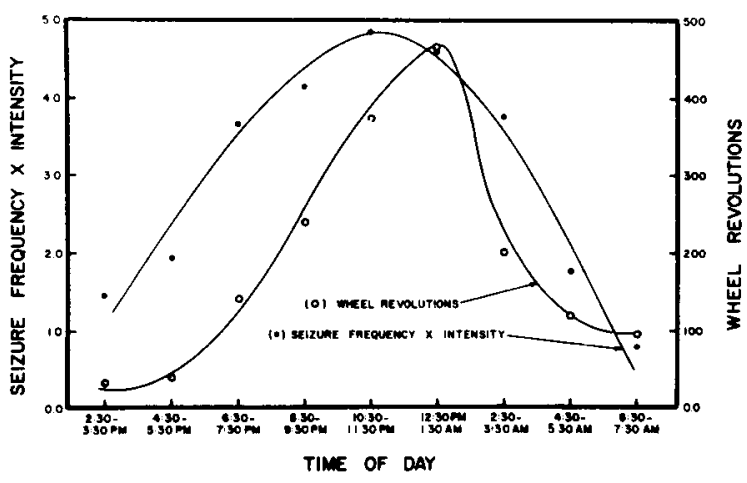

Fig. 2. Circadian cycle of seizure susceptibility and wheel activity.

gerbils over the critical hours beginning at 9:30 PM. The age ranged from two to 20 months. Additional seizure prone animals were obtained by screening a larger colony population. No testing of these animals had occurred during the previous week.

The results, while promising, were not conclusive. Hence we reconstructed groups of seven each from the same population in a random fashion and tested them at 2:30 to 7:30 PM and 4:30 to 7:30 AM. These animals had not been tested for two weeks previously. Mild seizures were given the score of two, and severe seizures the score of five. The seizure index seen in Fig. 2 is presented as an average seizure frequency by intensity for each 2-h period during an 18 -h test period. Fourteen animals are represented at each point. Wheel running data collected on 20 additional gerbils are plotted in the same figure so that the correspondence between the two measures can be seen.

Seizure susceptibility was the greatest around $12: 00 \mathrm{M}$ and was less both earlier and later. There is a strong correlation between susceptibility and behavioral activity $(r=.836 ; \mathrm{p}<.002)$, although our conclusions cannot be definite as the measures were taken on independent groups of animals.

\section{EXPERIMENT 5}

\section{DRUG MODIFICATION OF SEIZURE FREQUENCY}

Procedure and Results. In a further attempt to identify the characteristics of the seizures, 10 susceptible gerbils were injected IP with an average of $7.5 \mathrm{mg}$ of Diphenyl hydantoin Sodium (Dilantin) in $0.15 \mathrm{ml}$ of Ringer's solution. Ten additional seizureprone animals were given equal amounts of the Ringer's solution. Dilantin is an anticonvulsant drug typically administered to control epileptic seizures in humans. Alternate testing of drugged and nondrugged animals in the arena began $1 \mathrm{~h}$ after injection. None of the gerbils receiving Dilantin seized, whereas seven of the 10 gerbils given only Ringer's solution showed the usual seizure pattern $\left(\chi^{2}=10.76\right.$; df $\left.=1 ; p<.01\right)$. Clearly the drug was effective in controlling seizures in the gerbil.

A second drug, reserpine, was also effective in eliminating the seizure pattern. Eleven seizure-prone gerbils were injected IP with $0.25 \mathrm{mg}$ reserpine in $0.15 \mathrm{~m} 1$ of Ringer solution, while nine others received the vehicle only. Alternate testing of drugged and nondrugged animals in the open-field began $6 \mathrm{~h}$ after injection. None of the animals receiving reserpine seized, whereas five of the nine receiving Ringer injections showed the usual seizure response $\left(x^{2}=7.54 ; \mathrm{df}=1 ; \mathrm{p}<.01\right)$.

\section{DISCUSSION}

The data as a whole are highly supportive of the interpretation that the spontaneous seizure in the gerbil is related to the level of excitation in the central nervous system. Novelty (increased stimulus input), rather than stimulus form, provokes the seizure. Moreover, the convulsive behavior diminishes and recovers as expected of central habituation processes, is correlated with behavioral activation and attenuated by anticonvulsant drugs. The form of the seizure and its reaction to environmental stimuli and the drugs Dilantin and reserpine give it the appearance of epilepsy in man.

The underlying mechanisms remain unspecified. The diet of Purina Laboratory Chow with supplements of lettuce and sunflower seeds seems adequate. The animals show no neurological dysfunction other than that associated with the seizure, and brain histologies reveal no pathologies or middle-ear infection. ${ }^{2}$ Overcrowding and mishandling do not appear to be involved. No animal has died as a result of a seizure and all remain in apparent good health. Seizure susceptibility has been reported by our supplier, Victor Schwentker at Tumblebrook Farm (Brant Lake, $\mathrm{N}$. Y.), and the condition has also been found by a private individual. ${ }^{3}$ In a recent shipment of 60 gerbils from Tumblebrook Farm two seizing gerbils were found using our usual testing procedure. All of this indicates that the response does not seem peculiar to our particular laboratory or group of animals.

It is possible that water balance plays some role, since we provide our animals with water which they drink in substantial amounts $(\delta \overline{\mathrm{X}}=58.1 \mathrm{ml} / \mathrm{kg} / \mathrm{day} ; \quad \phi \overline{\mathrm{X}}=57.9 \mathrm{ml} / \mathrm{kg} / \mathrm{day})$ even though they ordinarily can live without it. Our only test for a hydration effect was unsuccessful because gerbils removed from water suffered dehydration effects within a few days. This apparent change in metabolic requirements is in itself interesting although it makes it difficult to assess the role of water balance in this setting.

There is an obvious familial transmission since the majority of our seizure-prone animals were derived from two breeding pairs. In one pair the male was affected and in the other pair the female was affected. Our data are most congruent with the hypothesis of a dominant autosomal condition with penetrance as a function of arousal level ( $64.9 \%$ of offspring derived from two pairs seized at some time). We are now involved in breeding studies to explore the mode of inheritance more fully.

\section{REFERENCES}

BARNETT, S. A. Social stress. In J. D. Carthy and C. L. Duddington (Eds.), Viewpoints in biology. London: Butterworths, 1964.

KING, H. D. Life processes in gray Norway rats during fourteen years in captivity. In C. R. Stockard and H. M. Evans (Eds.), The American Anatomical Memoirs, No. 17. Philadelphia: Wistar Institute, 1939.

KING, J. T., LEE, C. P., \& VISSCHER, M. B. Single versus multiple cage occupancy and convulsive frequency in $\mathrm{C} 3 \mathrm{H}$ mice. Procedures for the Society of Experimental Biology and Medicine. 1955, 88, 661-000.

RICHTER, C. P. On the phenomenon of sudden death in animals and man. Psychonom. Med., 1957, 19, 191-000.

\section{NOTES}

1. This research was supported by NIMH Grant MH 14076-01 and NIMH Research Development Award MH-11, 174-01 to D. D. T.

2. Dr. Chester A. Gleiser, Department of Veterinary Pathology, Texas A \& M University, kindly did the histologies and interpretations.

3. D. G. Robinson, Jr., Comdr., USN, Fort Leavenworth, Kansas. 